\title{
Progesterone therapy for the treatment of non-cancer cachexia: a systematic review
}

\author{
Joanne K Taylor, ${ }^{1}$ Neil Pendleton ${ }^{2}$
}

- Additional material is published online only. To view please visit the journal online (http://dx.doi.org/10.1136/ bmjspcare-2015-001041).

${ }^{1}$ East Lancashire Hospitals NHS Trust, Blackburn, UK

${ }^{2}$ Centre for Clinical and Cognitive Neurosciences, Institute of Brain, Behaviour and Mental Health, Salford Royal Hospital, Salford, UK

\section{Correspondence to}

Dr Joanne K Taylor; joanne.taylor111@gmail.com

Received 13 October 2015 Revised 18 January 2016

Accepted 4 April 2016 Published Online First 20 April 2016

\section{CrossMark}

\footnotetext{
To cite: Taylor JK, Pendleton N. BMJ Supportive \& Palliative Care 2016:6:276286.
}

\section{ABSTRACT}

Background Cachexia describes a complex pathological syndrome of muscle wasting, anorexia and weight loss. Progesterone therapies have been shown to improve appetite and promote weight gain in patients with cachexia; however, research has focused heavily on patients with cancer, and its effectiveness in other diseases remains unclear.

Aims This systematic review aimed to present the evidence available for progesterone therapy as a treatment for non-cancer cachexia.

Method Surrogate outcome measures used were weight change, lean body mass (LBM), muscle strength, appetite, health-related quality of life (HRQOL) and serum albumin. Both randomised and non-randomised trials were included. A literature search of clinical trials using the medical subject heading (MeSH) terms 'cachexia' OR 'anorexia' OR 'weight' OR 'frail (truncated)' OR 'appetite' OR 'wasting syndrome' PLUS 'megestrol acetate' OR 'medroxyprogesterone acetate' was performed. Results Eighteen studies were included in this review; 12 randomised control trials and 6 non-randomised trials. This collated results from 916 patients with HIV/AIDS, end-stage renal failure, chronic obstructive pulmonary disease (COPD) and geriatric cachexia. Metaanalysis comparing progesterone therapy with placebo concluded mean change in weight was not significant (mean difference (MD) 1.56, $95 \% \mathrm{Cl}-0.36$ to $3.52, \mathrm{p}=0.12$ ). There was little evidence to show significant impact on LBM, and no trials looked at muscle strength. There was a paucity of evidence looking at appetite and HRQOL; however, results were generally positive.

Conclusions Current evidence does not support the use of progesterone therapies for non-cancer cachexia. There may however be a limited role for its use as an appetite stimulant in a palliative context on a case-by-case basis.

\section{BACKGROUND}

\section{Cachexia}

Cachexia describes a pathological clinical syndrome characterised by weight loss, anorexia and muscle wasting. It is a clinical description associated with severe, advanced disease and poor prognosis. Cachexia is common in patients with advanced chronic disease with an estimated $25 \%$ of patients with chronic obstructive pulmonary disease (COPD) and $25-50 \%$ of patients with end-stage renal failure (ESRF) suffering from this syndrome. ${ }^{1} 2$ Cachexia is a distressing symptom for the patient and family, who fear their loved one 'wasting away' or 'starving to death'. 3

The underlying pathogenesis of cachexia remains an area of research; however, there is good evidence to show this is a multifactorial process mediated predominantly by proinflammatory cytokines. ${ }^{45}$ A variety of processes are known to contribute to this syndrome, including anorexia, hypercatabolism, muscle wasting, fatigue, reduced physical exercise, anaemia, raised inflammatory markers and endocrine abnormalities. ${ }^{6}$

Terminology remains variable with syndromes such as 'anorexia-cachexia syndrome' and 'wasting syndrome' used synonymously. While frequently described in clinical practice, there is a lack of international consensus defining the term 'cachexia'. In 2008, the Cachexia Consensus Working Group published a proposal for the following definition: 'Cachexia, is a complex metabolic syndrome associated with underlying illness and characterized by loss of muscle with or without loss of fat mass'. ${ }^{8}$ Within this publication, a set of diagnosis criteria were proposed. This is shown in box 1 below. 
Box 1

Diagnostic Criteria for Wasting Disease (Cachexia) in
Adults $^{8}$
Weight loss of at least $5 \%$ in 12 months or less in the
presence of underlying illness, PLUS THREE of the follow-
ing criteria:
Decreased muscle strength (lowest tertile)
Fatigue
Anorexia
Low fat-free mass index
Abnormal biochemistry
A. Increased inflammatory markers: CRP $(>5.0 \mathrm{mg} / \mathrm{L})$,
IL-6 ( $>4.0 \mathrm{pg} / \mathrm{mL})$
B. Anaemia $(<12 \mathrm{~g} / \mathrm{dL})$
C. Low serum albumin $(<3.2 \mathrm{~g} / \mathrm{dL})$
Reprinted from Evans et $a l l_{1}^{8}$ with permission from
Elsevier Limited.

This set of diagnostic criteria can be applied to cachexia secondary to any underlying condition. They have yet to be tested in clinical practice; however, they provide a framework for clinical research. Guidance for the diagnosis of cancer cachexia ${ }^{9}$ is more focused on weight loss and sarcopenia, however similarly reference anorexia signs of underlying inflammation.

\section{Treatment of cachexia}

Effective strategies to manage cachexia have been slow to evolve. Non-pharmacological strategies such as dietary advice, high-calorie diet and exercise have shown disappointing results. ${ }^{10-14}$ Pharmacological strategies have included progesterone therapy, anabolic steroids, cannabinoids, antidepressants, recombinant growth factor and more recently thalidomide and ghrelin hormone with mixed results. ${ }^{15-18}$

The mechanism of action of progesterone for cachexia is not fully understood. There are two commercially available progesterone therapy drugs for the treatment of anorexia/cachexia: megestrol acetate (MA) (Megace, Bristol-Myers Squibb) and medroxyprogesterone (Provera, Pharmacia and Climanor, ReSource Medical). The US Food and Drug Administration licensed MA for cachexia in patients with AIDS in 1993. Neither MA nor medroxyprogesterone is licensed for the treatment of cachexia in the UK, and at the time of writing, neither has been approved by the European Medicines Authority (EMA).

\section{Why is this research needed?}

A Cochrane review originally published in 2005 examined the use of MA for anorexia-cachexia syndrome. ${ }^{19}$ This review included all patient groups: patients with cancer, HIV/AIDS and other chronic disease, including cachexia associated with ageing. It concluded that there was sufficient evidence to show MA improves appetite and induces slight weight gain. The 2010 European Palliative Care Research Collaborative (EPCRC) Cachexia Guidelines recommended progesterone therapies 'should be considered for patients with refractory cachexia and with anorexia as a major distressing symptom' in patients with cancer. ${ }^{20}$ Both cited the lack of high-quality research evidence.

It remains unclear if the management of cachexia should be the same regardless of underlying aetiology. There has been an increasing use of MA in patients with cachexia with chronic disease, particularly in a palliative setting. However, the subgroup analyses in the Cochrane review of patients with AIDS or other underlying pathologies were not conclusive. Results were limited in the main part owing to the lack of randomised control trials (RCTs), and important domains such as lean body mass (LBM) were not included, questioning the benefit of any demonstrable weight gain.

This review aims to present an update of the current research looking at efficacy in patients without cancer, including subgroup analysis by underlying aetiology to guide physician's decision-making in this poorly researched area.

\section{METHODS}

This review is based on the methodology laid out in the Cochrane Handbook for Systematic Reviews of Interventions (CHSRI) and Preferred Reporting Items for Systematic Reviews and Meta-Analyses (PRISMA) statement. ${ }^{21} 22$ As there were no validated diagnostic criteria for cachexia, surrogate markers were used (based on current working definitions of the cachexia syndrome). A general review of adverse events and safety profile was performed. Meta-analysis of RCTs was performed where enough data were available. Anticipating a lack of data, we have also included a full description and analysis of all the available evidence including randomised and non-randomised trials.

\section{Eligibility criteria}

Studies considered for inclusion in this review were RCTs (both blinded and unblinded), non-randomised clinical trials and cross-over trials (both randomised and non-randomised). Studies must have been available in the English language. Trial participants were required to be over the age of 16 and have at least one of the following: clinically suspected cachexia, malnutrition, low body weight/body mass index (BMI), unintentional weight loss and low serum albumin. Patients with a diagnosis of active cancer were excluded. Although 'geriatric cachexia' remains a debatable term, it was not felt necessary to exclude these patients form our analysis. Any progesterone therapy administered using the oral route of administration was accepted. Comparison could be made with placebo, alternative doses, preparations and 
concentrations, or other medications/interventions. Trials with a dropout rate of $>50 \%$ were also excluded.

The measured outcomes of this review can be seen in box 2 below.

\section{Search methods}

Electronic searches were performed on the following databases: The Cochrane Central Register of Controlled Trials (CENTRAL), Medline, Embase and ClinicalTrials.gov.

\section{MeSH search terms}

- 'Trial' (or selected 'clinical trials' in search filter) PLUS

- 'Cachexia' OR 'anorexia' OR 'weight' OR 'frail (truncated)' OR 'appetite' OR 'wasting syndrome' PLUS

- 'Megestrol acetate' OR 'medroxyprogesterone acetate' A reference check was made of all included studies, and any papers of interest were screened using the criteria as above. Search terms were deliberately kept broad owing to the diverse terminology used for 'cachexia'. More narrow searched were trialled and important relevant studies were missed.

\section{Data collection and analysis}

Once all duplicate papers were deleted, abstracts were manually filtered by investigator JKT and irrelevant papers removed. Following this, all remaining papers were reviewed independently by two investigators (JKT and NP). Any studies where parties disagreed were discussed and a moderated decision about inclusion made. Data were managed on Microsoft Excel 2011 and Review Manager (RevMan) software (Collaboration RTC. Review Manager (RevMan). 5.2.

Box 2

\section{Outcomes}

1. Weight change

2. Subjective change in appetite

Various scoring systems were accepted provided they were adequately explained in methodology

3. Change in lean body mass (LBM)

LBM could be measured either directly by bioelectrical impedance scales or by anthropological measurements -for example, mid-arm circumference and triceps skinfold thickness. These are validated methods of measuring LBM. ${ }^{23} 24$

4. Muscle strength

Acceptable methods for measuring muscle strength included handgrip strength or knee flexion/extension strength.

5. Health-related quality of life (HRQOL) Various scoring systems were accepted provided they were adequately explained in methodology

6. Serum albumin
Copenhagen, The Nordic Cochrane Centre: The Cochrane Collaboration 2012). Data requests were sent to all authors in cases of missing/unpublished data where possible via email.

A risk-of-bias assessment was performed on RevMan for all included RCTs. The 'Jadad scale' checklist was used to assess the quality of RCTs. ${ }^{25}$

\section{Data analysis}

Meta-analysis was performed on outcomes where data were available from at least two RCTs. 'Mean change from baseline' was used for analysis of continuous variables. Data were analysed using either the inverse variance (IV) fixed-effects method or IV random-effects method. If heterogeneity was significant $\left(\mathrm{I}^{2}>30 \%\right)$, a random-effects model was used. Effect was measured using either mean difference (MD) or standardised mean difference (SMD). 95\% CIs and SDs were used for the analysis. A $p$ value of $<0.05$ was considered significant. Relative risk (RR) was used in all other analyses. The majority of studies identified for this review did not publish an intention-to-treat analysis; therefore, this review is not based on this principle.

\section{Quality of the evidence}

The Grading of Recommendations, Assessment, Development and Evaluations (GRADE) Working Group approach was used to assess the quality of evidence produced by this review. ${ }^{26}$

\section{MAIN RESULTS}

\section{Search results}

The main search was performed on 8 February 2014. A total of 1440 papers were identified. Figure 1 below lays out the filtering process to leave 18 remaining included studies. Most 'irrelevant' studies were related to progesterone therapy as a contraceptive or hormone replacement therapy. A further updated search was performed on 25 August 2015 , identifying 34 studies, none of which were relevant.

\section{Included studies}

Eighteen studies were ultimately included in this review as shown in table 1 . Of these, 12 were RCTs and 6 were non-randomised trials/pilot studies. Of the 12 RCTs, 4 compared progesterone therapy with placebo and 8 compared progesterone therapy with other interventions. This totalled 916 patients (HIV/ AIDS $n=607$, ESRF $n=95$, COPD $n=145$, geriatric cachexia $\mathrm{n}=69$ ).

The vast majority of studies looked at MA, with only one using medroxyprogesterone. ${ }^{33}$ Dose of MA was variable (range: $40 \mathrm{mg}-800 \mathrm{mg}$ a day, most common: $800 \mathrm{mg}$ a day). Trial length and timing of analysis was also variable (range: 3 weeks -7 months, most common timing of analysis was 12 weeks). 


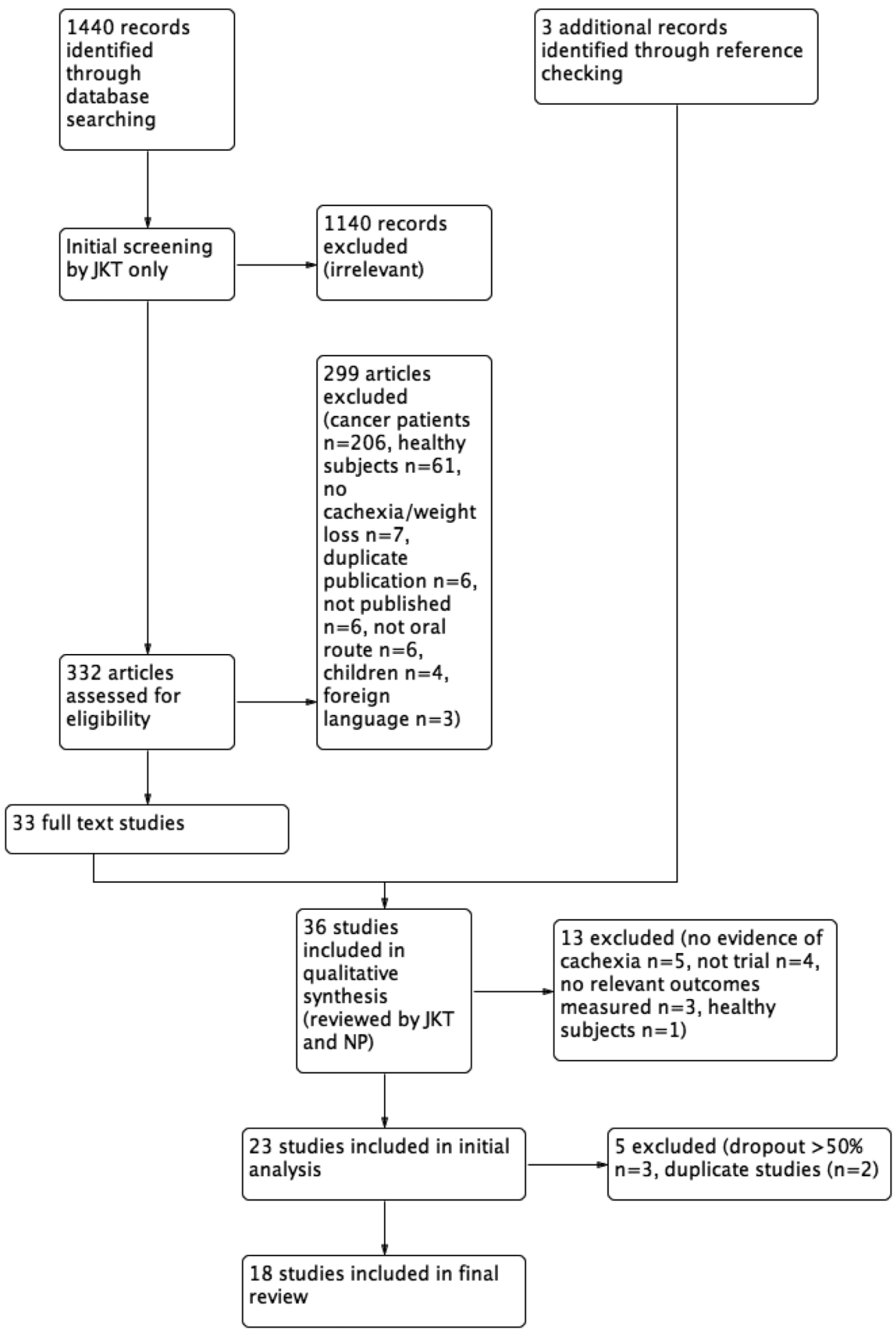

Figure 1 Study flow diagram.

\section{Characteristics of included studies and risk-of-bias assessment}

See online supplementary material.

\section{Data analysis}

Progesterone therapy versus placebo

By outcome

Weight change

Figure 2 below includes results from the meta-analysis comparing weight change using the random-effects IV model ( $\mathrm{I}^{2}$ 90\%-considerate heterogeneity). Adequate data were available from only three RCTs.

Underlying conditions were AIDS, COPD and geriatric cachexia. For all three studies, $800 \mathrm{mg}$ a day MA was used. $\mathrm{MD}$ was not statistically significant (MD $1.56,95 \% \mathrm{CI}-0.36$ to $3.52, \mathrm{p}=0.12$ ).

Data for change in weight were available from 12 studies; 7 RCTs, 5 non-randomised trials, 442 patients. $^{29} \quad 30 \quad 34 \quad 38 \quad 3942 \quad 43$ Mean weight change in patients receiving MA was positive in all studies, 
Table 1 Summary of included studies

\begin{tabular}{|c|c|c|c|c|c|c|}
\hline Study name & $\begin{array}{l}\text { Intervention total daily } \\
\text { dose (mg) }\end{array}$ & $\begin{array}{l}\text { Comparison } \\
\text { group(s) }\end{array}$ & $\begin{array}{l}\text { Underlying } \\
\text { condition }\end{array}$ & $\begin{array}{l}\text { Participants } \\
\text { (n) }\end{array}$ & $\begin{array}{l}\text { Length of trial } \\
\text { (weeks) }\end{array}$ & $\begin{array}{l}\text { Jadad } \\
\text { score }\end{array}$ \\
\hline \multicolumn{7}{|c|}{ Randomised control trials vs placebo } \\
\hline Monfared et al ${ }^{2}$ & $\begin{array}{l}\text { MA } \\
80\end{array}$ & Placebo & ESRF & 22 & 8 & 3 \\
\hline Von Roenn et al ${ }^{27}$ & $\begin{array}{l}\text { MA } \\
100 \text { v } 400 \text { v } 800\end{array}$ & Four-arm trial* & AIDS & 270 & 12 & 3 \\
\hline Weisberg et $\left.a\right|^{28}$ & $\begin{array}{l}\text { MA } \\
800\end{array}$ & Placebo & COPD & 145 & 8 & 3 \\
\hline Yeh et al ${ }^{29}$ & $\begin{array}{l}\text { MA } \\
800\end{array}$ & Placebo & Geriatric cachexia & 69 & 12 & 5 \\
\hline \multicolumn{7}{|c|}{ Randomised control trials vs other interventions } \\
\hline Batterham and Garsia ${ }^{30}$ & $\begin{array}{l}\text { MA } \\
400\end{array}$ & Three-arm trial: $\dagger$ & HIV & 15 & 12 & 2 \\
\hline Mulligan et $a \beta^{31}$ & $\begin{array}{l}\text { MA } \\
800\end{array}$ & MA plusł & HIV & 79 & 12 & 5 \\
\hline Mwamburi et $a \beta^{32}$ & $\begin{array}{l}\text { MA plus dietary advice } \\
800\end{array}$ & Oxandrolone & HIV & 39 & 8 & 3 \\
\hline Rochon et $a l^{33}$ & $\begin{array}{l}\text { Medroxyprogesterone plus§ } \\
400\end{array}$ & Placebo plus§ & HIV & 12 & 5 & 3 \\
\hline Summerbell et $\left.a\right|^{34}$ & $\begin{array}{l}\text { MA } \\
40 \text { plus }\end{array}$ & Cyproheptadine & HIV & 14 & 12 & 1 \\
\hline Timpone et $a /^{35}$ & $\begin{array}{l}\text { MA } \\
750\end{array}$ & Four-arm trial: ** & HIV & 50 & 12 & 2 \\
\hline Wanke et $a /^{\beta 6}$ & $\begin{array}{l}\text { MA concentrated solution } \\
575 \vee 800\end{array}$ & $\begin{array}{l}\text { Oral solution } \\
\text { (800 mg OD) }\end{array}$ & HIV & 63 & 12 & 3 \\
\hline Yeh et $a l^{37}$ & $\begin{array}{l}\text { MA } \\
800\end{array}$ & MA plust† & ESRF & 9 & 24 & 5 \\
\hline \multicolumn{7}{|l|}{ Non-randomised trials } \\
\hline Gołębiewska et a ${ }^{\beta 8}$ & $\begin{array}{l}\text { MA } \\
160\end{array}$ & & ESRF & 32 & $\begin{array}{l}\text { Up to } 6 \text { months } \\
\text { (analysis at } 8 \text { weeks) }\end{array}$ & \\
\hline Graham et a ${ }^{\beta 9}$ & $\begin{array}{l}\text { MA } \\
800\end{array}$ & & AIDS & 14 & 3 & \\
\hline Lien and Ruffenach ${ }^{40}$ & $\begin{array}{l}\text { MA } \\
40\end{array}$ & & ESRF & 16 & 8 & \\
\hline Mwamburi et a ${ }^{41}$ & $\begin{array}{l}\text { MA plus } \neq \neq \\
800\end{array}$ & & HIV & 29 & 7 months & \\
\hline Rammohan et $\left.a\right|^{42}$ & $\begin{array}{l}\text { MA } \\
400\end{array}$ & & ESRF & 16 & 16 & \\
\hline Von Roenn et a ${ }^{43}$ & $\begin{array}{l}\text { MA } \\
320 \text { plus§§ }\end{array}$ & & HIV & 22 & Up to 72 weeks & \\
\hline
\end{tabular}

*(a) $100 \mathrm{mg} \mathrm{OD,} \mathrm{(b)} 400 \mathrm{mg} \mathrm{OD,} \mathrm{(c)} 800 \mathrm{mg}$ OD and (d) placebo.

†(a) Dietary counselling (b) nandrolone decanoate (100 mg/fortnight intramuscular injection) (c) megestrol acetate (400 mg/day oral).

¥MA plus testosterone versus MA plus placebo.

$\S$ Nutritional support, amino acid supplementation and protein drinks.

शIncreased by $40 \mathrm{mg}$ alternate weeks to maximum dose of $160 \mathrm{mg}$ if no weight gain.

**(a) Dronabinol $2.5 \mathrm{mg} \mathrm{BD,} \mathrm{(b)} \mathrm{MA} 750 \mathrm{mg} \mathrm{OD,} \mathrm{(c)} \mathrm{MA} 750$ OD plus dronabinol $2.5 \mathrm{mg}$ BD and (d) MA $250 \mathrm{mg}$ OD plus dronabinol $2.5 \mathrm{mg}$ OD.

††Physical training versus placebo plus physical training.

$\ddagger \ddagger$ Dietary advice plus oxandrolone.

$\S \S$ Increased by $140 \mathrm{mg}$ if no weight gain after 12 weeks.

COPD, chronic obstructive pulmonary disease; ESRF, end-stage renal failure; MA, megestrol acetate.

ranging from $0.86 \mathrm{~kg}$ to $10.2 \mathrm{~kg}$ over a follow-up period ranging from 3 weeks to 72 weeks. Mean weight change was only significant in four studies. A clear dose-response gradient with MA was seen in the Von Roenn et $a l^{27}$ study (mean weight change $0.86 \mathrm{~kg}$, SD 4.61 with $100 \mathrm{mg}$ a day $(\mathrm{n}=61) ; 1.91 \mathrm{~kg}$, SD 4.3 with $400 \mathrm{mg}$ a day $(\mathrm{n}=53)$; and $3.54 \mathrm{~kg}$, SD 4.3 with $800 \mathrm{mg}$ a day $(\mathrm{n}=53))$, although no changes were statistically significant.

\section{Change in LBM}

Data for change in LBM were available from 6 studies; 5 RCTs, 1 non-randomised trial, 342 patients. ${ }^{27-30} 3642$ There were inadequate available RCT data to perform meta-analysis. Four studies used bioelectrical impedance (three reporting fat-free mass (FFM) and one reporting LBM) and two reported anthropological measurements. Five of the six studies reported an increase in mean LBM in patients 


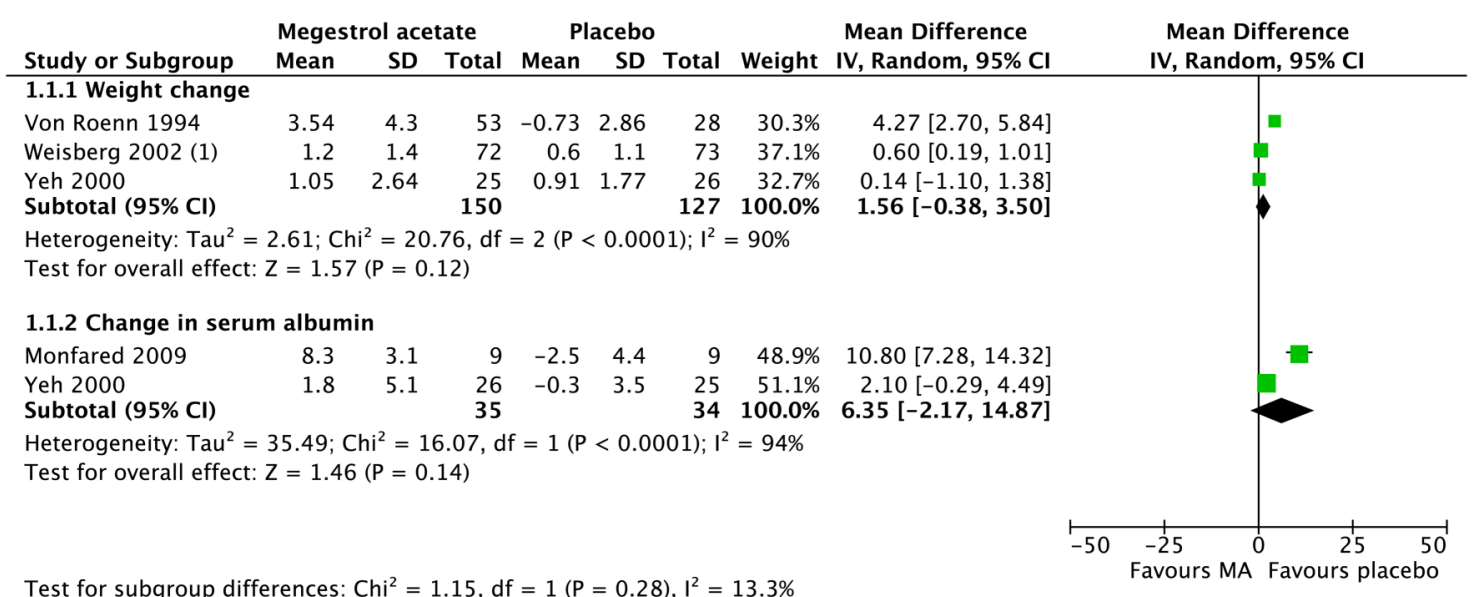

(1) data used at 2 weeks

Figure 2 Megestrol acetate versus placebo: weight change and change in serum albumin.

receiving MA; however, only one reported significant gain (mean change in FFM $2.76 \mathrm{~kg}$, SD 0.55 ). ${ }^{30} \mathrm{~A}$ clear dose-response gradient with MA was also seen in the Von Roenn $e^{2} a l^{27}$ study.

\section{Appetite}

Raw data were available from 3 studies; 2 RCTs, 1 non-randomised trial, 181 patients. ${ }^{27} 3042$ Appetite was measured using a variety of visual scales and questionnaires. There were inadequate raw data to perform meta-analysis. All three studies reported most participants receiving MA reported increased appetite (range 72-100\%, mean 79\% (143/181)). In the Von Roenn et $a l^{27}$ study, a significant dose-response relationship was seen, as well as a significant improvement in appetite compared with placebo (MA $800 \mathrm{mg}$ vs placebo: RR $1.85,95 \%$ CI 1.27 to $2.70, \mathrm{p}=0.001$, $\mathrm{n}=83$ ).

\section{Muscle strength}

No study measured muscle strength (although Weisberg et $_{\mathrm{al}} \mathrm{l}^{28}$ looked at respiratory muscle strength, this was not felt to be synonymous with overall muscle strength).

\section{Health-related quality of life (HRQOL)}

Results were available from 4 studies; 1 RCT, 3 nonrandomised trials, 205 patients ${ }^{27} 38 \quad 42 \quad 43$ using a variety of visual analogue scales and questionnaires. Pooling together all available data, in 61\% (126/205) of the patients receiving MA, HRQOL scores increased (range 44-100\%). As in other outcomes, there was a clear dose-response gradient seen with MA in the Von Roennet $a l^{27}$ study, with a significant improvement in QOL measures when comparing MA $800 \mathrm{mg}$ a day with placebo (RR 3.0, 95\% CI 1.43 to $6.26, \mathrm{p}=0.004, \mathrm{n}=81$ ).

\section{Serum albumin}

Meta-analysis was performed with data from two studies: Monfared $e t a l^{2}$ and $\mathrm{Yeh}^{37}$ (as shown in figure 2). Underlying conditions were ESRF and geriatric cachexia. MD was not statistically significant comparing MA with placebo (MD 6.35, 95\% CI -2.17 to 14.87, $\mathrm{p}=0.14$ ).

Overall, results were available from 6 studies; 3 RCTs, 3 non-randomised trials, 128 patients. $^{2} 3036384042$ Mean change in serum albumin in patients receiving MA was positive in five of the six studies; however, this was statistically significant in only one study (mean change $8.3 \mathrm{~g} / \mathrm{L}, \mathrm{SD} 3.1)^{2}$

\section{Analysis by underlying condition \\ HIVIAIDS}

Eleven studies looked at patients with HIV/AIDS; 8 RCTs, 3 non-randomised trials, 607 patients (see table 1). Mean weight gain was significant in three of the six studies; however, unfortunately only one RCT compared directly with placebo, limiting analysis. Mean weight gain ranged from 0.86 to $10.2 \mathrm{~kg}$. One study $^{30}$ showed significant gain in LBM, and one other showed a significant improvement in appetite and HRQOL measures. ${ }^{27}$

\section{End-stage renal failure (ESRF)}

Five studies looked at patients with ESRF; 2 RCTs, 3 non-randomised trials, 95 patients. Yeh et $a l^{37}$ found a significant improvement in weight and exercise tolerance. Monfared et $a l^{2}$ primarily looked at serum albumin, reporting a significant improvement in malnourished dialysis patient. All three clinical trials showed generally positive results.

\section{Chronic obstructive pulmonary disease (COPD)}

One study looked at patients with COPD. ${ }^{28}$ This was an RCT with 145 participants. Using MA $800 \mathrm{mg}$ a day for 8 weeks, this study reported a significant 
improvement in appetite and body weight, as well as ventilation and improved body image (no improvement in respiratory muscle function or exercise tolerance).

\section{Geriatric cachexia}

One study looked at patients with geriatric cachexia. ${ }^{37}$ This was an RCT with 69 participants. Using MA $800 \mathrm{mg}$ a day for 12 weeks, this study reported a significant improvement in appetite and well-being, but no statistically significant weight gain.

\section{Comparison with other treatments for cachexia}

The studies Batterham and Garsia ${ }^{30}$ and Mwumburi et $a l^{32}$ compared progesterone therapy with anabolic steroids. Meta-analysis comparing effect on weight change and LBM showed no observed significant difference (as shown in figures 3 and 4 below). Weight change: MD 2.90, 95\% CI -2.83 to $8.64, \mathrm{p}=0.32$ ( $\mathrm{I}^{2} 80 \%$, random-effects IV model used). Change in LBM: SMD $-0.23,95 \% \mathrm{CI}-0.85$ to $0.38, \mathrm{p}=0.45$ (SMD used as different outcome measures used) FFM vs LBM, I ${ }^{2} 0 \%$, fixed-effects IV model used. Owing to high variability in data and study design, no other supplementary analysis has been made.

\section{Adverse events}

Adverse event data were available from 11 studies. There were no deaths reported to be considered related to progesterone therapy. Von Roenn et al, ${ }^{43}$ Von Roenn $e t a l^{27}$ and Yeh et $a l^{37}$ reported thromboembolic events in patients receiving MA (one case out of 22 participants, one case out of 270 participants and two cases out of 69 participants, respectively). No proven cases of adrenal insufficiency were reported. Data looking at the incidence of oedema were variably published; however, most studies reported this as a common adverse effect. There were three reported cases of hyperglycaemia/poor diabetic control on starting MA. ${ }^{35} 38{ }^{42}$ Other commonly reported side effects include dyspnoea/respiratory complaints, gastrointestinal upset, loss of libido/impotence and generalised weakness.

\section{DISCUSSION}

\section{Efficacy}

At the time of this review, there were 12 published RCTs and 7 non-randomised trials looking at the use of progesterone therapy for non-cancer cachexia, totalling 916 patients. Included studies were obtained from a literature search looking at multiple surrogate outcome measures for this complex syndrome. The underlying condition in the majority of patients in this analysis was HIV/AIDS. Meta-analyses were limited due to a lack of conformity with regard to methodology and patient groups, and raw data availability. While most studies reported improved outcomes, the quality of the evidence was poor and results variable. This review has therefore concluded that progesterone therapy has not been shown to be effective in the treatment of non-cancer cachexia. It is difficult to ascertain definitively if this is due to the lack of adequately powered randomised trials, or lack of effect. The largest scale RCT (270 participants $)^{27}$ did show a dose-response effect, but this was not significant for weight and LBM. Therefore, any effect is likely to be very small and of doubtful clinical significance. The current evidence does however suggest that progesterone therapies may have a positive impact on symptom control, particularly appetite. Most studies with positive results have used MA 400$800 \mathrm{mg}$ a day for 8-12 weeks safely. No trial demonstrated efficacy at a dose $<160 \mathrm{mg}$ a day, or treatment for $<8$ weeks. The duration of effect is unclear. These results are summarised in table 2.

As discussed in the introduction section, cachexia encompasses much more than just low body weight, and many would argue crude 'weight' is not the most useful outcome measure in this complex patient group. Only half of the studies included in this review measured LBM, with only one study reporting statistically significant results. No studies measured muscle strength. It should be noted that water retention is a common, recognised side effect of progesterone therapy; thus, the nutritional effect of any observed weight gain is unclear. The best way of measuring muscle mass has been debated. The most effective techniques include cross-sectional imaging and dual-energy X-ray absorptiometry (DEXA) scanning; however, these are expensive and time-consuming (and rarely done in clinical practice). Methods such as bioelectrical impedance and anthropological measurements are simple and cheap; however, accuracy in patients at the extremes of age and body habitus has been questioned. ${ }^{44}{ }^{45}$ Recent guidelines for the

\begin{tabular}{|c|c|c|c|c|c|c|c|c|c|c|}
\hline Study or Subgroup & \multicolumn{3}{|c|}{ Megestrol acetate } & \multicolumn{3}{|c|}{ Anabolic steroid } & Weight & $\begin{array}{l}\text { Mean Difference } \\
\text { IV, Random, } 95 \% \mathrm{CI}\end{array}$ & \multicolumn{2}{|l|}{$\begin{array}{l}\text { Mean Difference } \\
\text { IV, Random, } 95 \% \text { CI }\end{array}$} \\
\hline Batterham 2001 (1) & 10.2 & 4.51 & 4 & 4.01 & 1.68 & 8 & $44.2 \%$ & $6.19[1.62,10.76]$ & \begin{tabular}{l|l} 
& $-1+-$
\end{tabular} & \\
\hline Mwamburi 2004 (2) & 2.8 & 4.3 & 18 & 2.5 & 2.4 & 15 & $55.8 \%$ & $0.30[-2.03,2.63]$ & & \\
\hline Total $(95 \% \mathrm{CI})$ & & & 22 & & & 23 & $100.0 \%$ & $2.90[-2.83,8.64]$ & & \\
\hline \multicolumn{8}{|c|}{$\begin{array}{l}\text { Heterogeneity: } \mathrm{Tau}^{2}=13.92 ; \mathrm{Chi}^{2}=5.07, \mathrm{df}=1(\mathrm{P}=0.02) ; \mathrm{I}^{2}=80 \% \\
\text { Test for overall effect: } \mathrm{Z}=0.99(\mathrm{P}=0.32)\end{array}$} & Favo & $\begin{array}{lllc}-50 & -25 & 0 & 25 \\
\text { ours anabolic steroid } & \text { Favours MA }\end{array}$ & $\overrightarrow{50}$ \\
\hline
\end{tabular}

(1) Nandrolone decanoate

(2) Oxandrolone

Figure 3 Megestrol acetate versus anabolic steroid: weight change. 


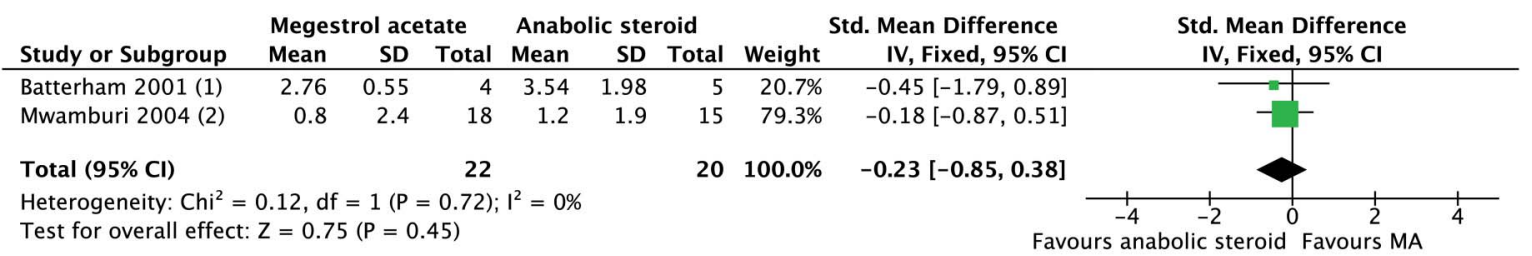

(1) Nandrolone decanoate

(2) Oxandrolone

Figure 4 Megestrol acetate versus anabolic steroid: change in lean body mass.

identification of cachexia have differed slightly in their recommendations for muscle mass measurements. ${ }^{8}{ }^{9}$ We suggest collection of muscle mass data should be included in any future studies; however, careful consideration of chosen measurement techniques should be made.

Markers of improved symptom control are of great significance in cachexia where aetiology is often multifactorial and irreversible. One study dominated results in this area, ${ }^{27}$ showing a clear dose-response gradient for appetite and HRQOL for patients with HIV. Weisberg $e t a l^{28}$ demonstrated improved appetite and improved body image in patients with COPD, and Yeh et $\mathrm{ll}^{37}$ showed improved appetite and well-being in patients with geriatric cachexia. These results are promising and may justify the use of progesterone therapies in palliative patients where QOL rather than nutritional status is the priority. It would be useful for further studies to focus more clearly on the impact on symptom control as current evidence is of low quality.

Serum albumin is an interesting outcome measure. Biochemical markers of nutritional status are influenced by many outside factors and may not give an accurate picture of overall nutritional health. Meta-analysis looking at the impact of MA on serum albumin showed insignificant results. This outcome has not been measured in other reviews, so no comparison can be made to current literature. It should be noted that most data for this outcome were gained from patients with ESRF, thus potential confounding factors are significant when applying these results to a wider cohort (eg, impact of dialysis).

Heterogeneity was extremely high in this review, with a huge variation in dose of progesterone, length of treatment and duration of follow-up-all of which could have influenced results. Besides this, the diversity of patient characteristics was great, with a spectrum of underlying conditions, comorbidities and prognoses. Studies looking at HIV/AIDS have provided the majority of data for this review, making up $66 \%$ of the total patients included. It is difficult to say if this could skew results when applied to all patients; however, looking at magnitude of weight gain, this was varied but of a similar trend across all disease

Table 2

\begin{tabular}{|c|c|c|c|c|}
\hline Outcome & Meta-analysis & Other analysis & Conclusion & Quality of evidence \\
\hline Weight change & $\begin{array}{l}\text { No significant change in weight } \\
\text { compared with placebo or } \\
\text { anabolic steroids. }\end{array}$ & $\begin{array}{l}\text { Compared with placebo, mean } \\
\text { weight gain was positive in all } \\
\text { included studies (significant in } \\
\text { four). }\end{array}$ & $\begin{array}{l}\text { Progesterone therapy is likely to } \\
\text { cause a small increase in weight. }\end{array}$ & GRADE scale: moderate \\
\hline LBM & $\begin{array}{l}\text { Insufficient data to compare with } \\
\text { placebo. } \\
\text { Comparison with anabolic } \\
\text { steroids: no significant difference. }\end{array}$ & $\begin{array}{l}\text { Five of the six studies where data } \\
\text { were available reported an } \\
\text { increase in mean LBM (significant } \\
\text { in one). }\end{array}$ & $\begin{array}{l}\text { Progesterone therapy may cause a } \\
\text { small increase in LBM, but this is } \\
\text { unlikely to be of any significant } \\
\text { magnitude. }\end{array}$ & GRADE scale: low \\
\hline Appetite & Insufficient data. & $\begin{array}{l}\text { All three studies where data were } \\
\text { available reported significant } \\
\text { improvement in appetite. Two } \\
\text { others also reported significant } \\
\text { results. }\end{array}$ & $\begin{array}{l}\text { Progesterone therapy is likely to } \\
\text { cause an improvement in appetite. }\end{array}$ & GRADE scale: low \\
\hline Muscle strength & No study measured this outcome. & Nil & $\begin{array}{l}\text { There is no evidence to show } \\
\text { progesterone therapy has any } \\
\text { influence over muscle strength. }\end{array}$ & \\
\hline HRQOL & Insufficient data. & $\begin{array}{l}\text { In all four studies, mean change in } \\
\text { HRQOL measures was positive } \\
\text { (but unclear is significantly so). }\end{array}$ & $\begin{array}{l}\text { Progesterone therapy may cause } \\
\text { some improvement in HRQOL } \\
\text { measures. }\end{array}$ & GRADE scale: low \\
\hline Serum albumin & $\begin{array}{l}\text { No significant change in serum } \\
\text { albumin compared with placebo. }\end{array}$ & $\begin{array}{l}\text { In five of the six studies where } \\
\text { data were available, mean change } \\
\text { in serum albumin was positive } \\
\text { (only significant in one study). }\end{array}$ & $\begin{array}{l}\text { Progesterone therapy may cause a } \\
\text { small increase in serum albumin. }\end{array}$ & GRADE scale: low \\
\hline
\end{tabular}

GRADE, Grading of Recommendations, Assessment, Development and Evaluations; HRQOL, health-related quality of life; LBM, lean body mass. 
groups (mean weight gain ranged from 0.86 to $10.2 \mathrm{~kg}$ in studies looking at HIV/AIDS, $1.2-9 \mathrm{~kg}$ in ESRF, 3.2 in COPD and 1.05 in geriatric cachexia). It is difficult to compare other outcomes owing to a lack of raw data.

\section{Safety profile}

Progesterone therapy appeared to be relatively safe with a limited range of serious adverse effects. This review included 916 patients, with no deaths reported to be linked to progesterone therapy. The rate of thromboembolic events from pooled data was approximately 1\% (4/361). The 2005 Cochrane review (looking at all patients with cachexia) performed a safety analysis including over 3000 patients. This concluded that mortality rates were increased in patients receiving MA, and risk appeared to be greater with higher doses (RR 1.43, 95\% CI 1.05 to 1.96). A large retrospective case-controlled study of 709 nursing home patients with weight loss in America also reported increased mortality in patients receiving MA. ${ }^{46}$ The reason for this remains unclear; however, the Cochrane review also reported a slightly higher (but insignificant) increase in rates of thromboembolic phenomenon in patients receiving MA.

The most common serious adverse events appear to be secondary to progesterone's glucocorticoid effect. While this review found no proven case of adrenal insufficiency, there is good evidence in the literature to suggest this can be an adverse effect. ${ }^{47-49}$ A report by the US Food and Drug Administration in 1997 acknowledged these adverse effects. ${ }^{50}$ Therefore, clinicians should be aware of these when initiating/withdrawing therapy.

\section{Limitations of this review}

The methodology of this review was limited by available resources. The majority of data extraction and analysis was performed by JKT only. Ideally, this process should have been performed by two or more independent investigators. A significant 'recurring theme' during this review was missing data. Analysis was limited in the main part owing to the lack of published raw data, or unclear statistical methods. Only four authors responded to data requests. 'Dealing with missing data' is a common problem, and it's impact on results is difficult to predict.

No trial included patients based on a diagnosis of 'cachexia' using diagnostic scores as described in the introduction section. This was anticipated as these scores do not seem to be widely used. Unfortunately, it was not possible to perform any analysis of efficacy based on severity of symptoms owing to poor data quality. Broad 'inclusion criteria' has meant potentially patients without true cachexia have been included, particularly those with pure weight loss without cachexia, or sarcopenia. It was difficult to devise a way around this problem without excluding a significant number of studies; therefore, conclusions should be made with this caveat.

\section{AUTHOR'S CONCLUSIONS}

There is a lack of evidence to demonstrate progesterone therapy causes nutritionally significant weight gain in patients with non-cancer cachexia; thus, its routine clinical use cannot be recommended. Its impact on symptoms such as appetite and HRQOL however is generally positive (but evidence is of low quality). This review did not find any evidence of increased mortality in patients receiving progesterone therapy; however, larger reviews including patients with cancer have reported increased mortality rates, possibly due to increased risk of venous thromboembolism. Other serious adverse events include adrenal insufficiency, and clinicians should be aware of this if initiating and withdrawing therapy. Fluid retention is a commonly reported side effect and may account for some observed weight gain. These findings are broadly similar to those made in the Cochrane Review of Megestrol acetate for anorexiacachexia syndrome and the EPCRC Cachexia Guidelines 2011. ${ }^{20}$ Despite repeated calls for greater research in this field, there remains a lack of good-quality trial data, particularly in patients without cancer.

\section{Implications for practice}

This review does not currently recommend the routine use of progesterone therapy for cachexia in patients without cancer. It may be justified with the aim of improving symptom control in a palliative context, however only on a case-by-case basis with appreciation of its adverse effect profile.

\section{Implications for research}

The quality of evidence remains poor, and more RCTs of progesterone therapy for patients with conditions such as HIV/AIDS, ESRF, COPD and geriatric cachexia are required. An increased focus on outcome measures such as LBM, muscle strength/functional status and HRQOL would be helpful to clarify the efficacy of progesterone therapies with appetite stimulation.

Acknowledgements The authors would like to acknowledge the contributions of Marshall Dozier (Senior Liaison Librarian for the College of Medicine and Veterinary Medicine) for advice regarding the literature search.

Competing interests None declared.

Provenance and peer review Not commissioned; externally peer reviewed.

\section{REFERENCES}

1 Wagner PD. Possible mechanisms underlying the development of cachexia in COPD. Eur Respir J 2008;31:492-501.

2 Monfared A, Heidarzadeh A, Ghaffari M, et al. Effect of megestrol acetate on serum albumin level in malnourished 
dialysis patients. J Ren Nutr 2009;19:167-71. http:// onlinelibrary.wiley.com/o/cochrane/clcentral/articles/038/ CN-00701038/frame.html

3 Marín Caro MM, Laviano A, Pichard C. Impact of nutrition on quality of life during cancer. Curr Opin Clin Nutr Metab Care 2007;10:480-7.

4 Argilés JM, Busquets S, Moore-Carrasco R, et al. The role of cytokines in cancer cachexia. Cachexia and Wasting: A Modern Approach. Springer, 2006:467-75.

5 Morley JE, Thomas DR, Wilson MM. Cachexia: pathophysiology and clinical relevance. Am J Clin Nutr 2006;83:735-43.

6 Pi-Sunyer FX. Overnutrition and undernutrition as modifiers of metabolic processes in disease states. Am J Clin Nutr 2000;72:533S-7S.

7 Borst SE. The role of TNF-alpha in insulin resistance. Endocrine 2004;23:177-82.

8 Evans WJ, Morley JE, Argilés J, et al. Cachexia: a new definition. Clin Nutr 2008;27:793-9.

9 Fearon K, Strasser F, Anker SD, et al. Definition and classification of cancer cachexia: an international consensus. Lancet Oncol 2011;12:489-95.

10 Bruera E. ABC of palliative care. Anorexia, cachexia, and nutrition. BMJ 1997;315:1219-22.

11 Slinde F, Grönberg AM, Engström CP, et al. Individual dietary intervention in patients with COPD during multidisciplinary rehabilitation. Respir Med 2002;96:330-6.

12 Fearon KC. Cancer cachexia: developing multimodal therapy for a multidimensional problem. Eur J Cancer 2008;44:1124-32.

13 Fearon K, Von Meyenfeldt M, Moses A, et al. Effect of a protein and energy dense N-3 fatty acid enriched oral supplement on loss of weight and lean tissue in cancer cachexia: a randomised double blind trial. Gut 2003;52:1479-86.

14 Grande AJ, Silva V, Riera R, et al. Exercise for cancer cachexia in adults. Cochrane Database Syst Rev 2014;11:CD010804.

15 Malkin CJ, Pugh PJ, West JN, et al. Testosterone therapy in men with moderate severity heart failure: a double-blind randomized placebo controlled trial. Eur Heart J 2006;27:57-64.

16 Jatoi A, Windschitl HE, Loprinzi CL, et al. Dronabinol versus megestrol acetate versus combination therapy for cancer-associated anorexia: a North Central Cancer Treatment Group study. J Clin Oncol 2002;20:567-73.

17 Gullett NP, Hebbar G, Ziegler TR. Update on clinical trials of growth factors and anabolic steroids in cachexia and wasting. Am J Clin Nutr 2010;91:1143S-7S.

18 Reid J, Mills M, Cantwell M, et al. Thalidomide for managing cancer cachexia. Cochrane Database Syst Rev 2012;4: CD008664.

19 Ruiz Garcia V, López-Briz E, Carbonell Sanchis R, et al. Megestrol acetate for treatment of anorexia-cachexia syndrome. Cochrane Database Syst Rev 2013;3:CD004310. http://onlinelibrary.wiley.com/doi/10.1002/14651858. CD004310.pub3/abstract

20 Radbruch L, Elsner F, Trottenberg P, et al. Clinical practice guidelines on cancer cachexia in advanced cancer patients. Aachen, Department of Palliative Medicinen/ European Palliative Care Research Collaborative, 2010.

21 Higgins JP, Green S. Cochrane handbook for systematic reviews of interventions. Wiley Online Library, 2008.
22 Moher D, Liberati A, Tetzlaff J, et al. Preferred reporting items for systematic reviews and meta-analyses: the PRISMA statement. Ann Intern Med 2009;151:264-9.

23 Segal K, Van Loan M, Fitzgerald P, et al. Lean body mass estimation by bioelectrical impedance analysis: a four-site cross-validation study. Am J Clin Nutr 1988;47:7-14.

24 Lean M, Han TS, Deurenberg P. Predicting body composition by densitometry from simple anthropometric measurements. Am J Clin Nutr 1996;63:4-14.

25 Jadad AR, Moore RA, Carroll D, et al. Assessing the quality of reports of randomized clinical trials: is blinding necessary? Control Clin Trials 1996;17:1-12.

26 Guyatt GH, Oxman AD, Vist GE, et al. GRADE: an emerging consensus on rating quality of evidence and strength of recommendations. BMJ 2008;336:924-6.

27 Von Roenn JH, Armstrong D, Kotler DP, et al. Megestrol acetate in patients with AIDS-related cachexia. Ann Intern Med 1994;121:393-9.

28 Weisberg J, Wanger J, Olson J, et al. Megestrol acetate stimulates weight gain and ventilation in underweight COPD patients. Chest 2002;121:1070-8. http://onlinelibrary.wiley. com/o/cochrane/clcentral/articles/465/CN-00379465/frame. html

29 Yeh SS, Wu SY, Lee TP, et al. Improvement in quality-of-life measures and stimulation of weight gain after treatment with megestrol acetate oral suspension in geriatric cachexia: results of a double-blind, placebo-controlled study. J Am Geriatr Soc 2000;48:485-92.

30 Batterham MJ, Garsia R. A comparison of megestrol acetate, nandrolone decanoate and dietary counselling for HIV associated weight loss. Int J Androl 2001;24:232-40.

31 Mulligan K, Zackin R, Roenn JH, et al. Testosterone supplementation of megestrol therapy does not enhance lean tissue accrual in men with human immunodeficiency virus-associated weight loss: a randomized, double-blind, placebo-controlled, multicenter trial. J Clin Endocrinol Metab 2007;92:563-70. http://onlinelibrary.wiley.com/o/cochrane/ clcentral/articles/858/CN-00576858/frame.html

32 Mwamburi DM, Gerrior J, Wilson IB, et al. Comparing megestrol acetate therapy with oxandrolone therapy for HIV-related weight loss: similar results in 2 months. Clin Infect Dis 2004;38:895-902. http://onlinelibrary.wiley.com/o/ cochrane/clcentral/articles/310/CN-00472310/frame.html

33 Rochon C, Prod'homme M, Laurichesse H, et al. Effect of medroxyprogesterone acetate on the efficiency of an oral protein-rich nutritional support in HIV-infected patients. Reprod Nutr Dev 2003;43:203-14.

34 Summerbell CD, Youle M, McDonald V, et al. Megestrol acetate vs cyproheptadine in the treatment of weight loss associated with HIV infection. Int J STD AIDS 1992;3:278-80. http://onlinelibrary.wiley.com/o/cochrane/clcentral/articles/384/ CN-00086384/frame.html

35 Timpone JG, Wright DJ, Li N, et al. The safety and pharmacokinetics of single-agent and combination therapy with megestrol acetate and dronabinol for the treatment of HIV wasting syndrome. The DATRI 004 Study Group. Division of AIDS Treatment Research Initiative. AIDS Res Hum Retroviruses 1997;13:305-15. http://onlinelibrary.wiley.com/o/ cochrane/clcentral/articles/722/CN-00137722/frame.html

36 Wanke C, Gutierrez J, Kristensen A, et al. Safety and efficacy of two preparations of megestrol acetate in HIV-infected individuals with weight loss in Africa, India, and the United 
States. J Appl Res 2007;7. http://onlinelibrary.wiley.com/o/ cochrane/clcentral/articles/393/CN-00642393/frame.html

37 Yeh SS, Marandi M, Thode HC Jr, et al. Report of a pilot, double-blind, placebo-controlled study of megestrol acetate in elderly dialysis patients with cachexia. J Ren Nutr 2010;20:52-62. http://onlinelibrary.wiley.com/o/ cochrane/clcentral/articles/786/CN-00741786/frame.html

38 Gołębiewska JE, Lichodziejewska-Niemierko M, Aleksandrowicz-Wrona E, et al. Influence of megestrol acetate on nutrition, inflammation and quality of life in dialysis patients. Int Urol Nephrol 2012;44:1211-22. http:// onlinelibrary.wiley.com/o/cochrane/clcentral/articles/768/ CN-00848768/frame.html

39 Graham KK, Mikolich DJ, Fisher AE, et al. Pharmacologic evaluation of megestrol acetate oral suspension in cachectic AIDS patients. J Acquir Immune Defic Syndr 1994;7: 580-6.

40 Lien Y, Ruffenach S. Low dose megestrol increases serum albumin in malnourished dialysis patients. Int J Artif Organs 1996;19:147-50.

41 Mwamburi DM, Gerrior J, Wilson IB, et al. Combination megestrol acetate, oxandrolone, and dietary advice restores weight in human immunodeficiency virus. Nutr Clin Pract 2004;19:395-402.

42 Rammohan M, Kalantar-Zadeh K, Liang A, et al. Megestrol acetate in a moderate dose for the treatment of malnutrition-inflammation complex in maintenance dialysis patients. J Ren Nutr 2005;15:345-55.

43 Von Roenn JH, Murphy RL, Wegener N. Megestrol acetate for treatment of anorexia and cachexia associated with human immunodeficiency virus infection. Semin Oncol 1990;17(6 Suppl 9):13-6.

44 Rolland Y, Czerwinski S, Abellan Van Kan G, et al. Sarcopenia: its assessment, etiology, pathogenesis, consequences and future perspectives. J Nutr Health Aging 2008;12:433-50.

45 Cruz-Jentoft AJ, Baeyens JP, Bauer JM, et al., European Working Group on Sarcopenia in Older People. Sarcopenia: European consensus on definition and diagnosis Report of the European Working Group on Sarcopenia in Older People. Age Ageing 2010;39:412-23.

46 Bodenner D, Spencer T, Riggs AT, et al. A retrospective study of the association between megestrol acetate administration and mortality among nursing home residents with clinically significant weight loss. Am J Geriatr Pharmacother 2007;5:137-46.

47 Subramanian S, Goker H, Kanji A, et al. Clinical adrenal insufficiency in patients receiving megestrol therapy. Arch Intern Med 1997;157:1008-11.

48 Naing KK, Dewar JA, Leese GP. Megestrol acetate therapy and secondary adrenal suppression. Cancer 1999;86:1044-9.

49 Chidakel AR, Zweig SB, Schlosser JR, et al. High prevalence of adrenal suppression during acute illness in hospitalized patients receiving megestrol acetate. J Endocrinol Invest 2006;29:136-40.

50 Mann M, Koller E, Murgo A, et al. Glucocorticoidlike activity of megestrol: a summary of food and drug administration experience and a review of the literature. Arch Intern Med 1997;157:1651-6. 